\title{
POLÍtICAS ATIVAS DE EMPREGO NA SOCIEDADE DE RISCO: EMANCIPAÇÃO OU REGULAÇÃO?
}

\author{
ACTIVE LABOUR MARKET POLICIES IN RISK SOCIETY: \\ EMANCIPATION OR REGULATION?
}

\author{
Clara Cruz Santos ${ }^{1}$ \\ Cristina Vanessa Coimbra Nunes ${ }^{2}$
}

\section{RESUMO}

As transformações ocorridas na passagem da primeira para a segunda modernidade no mercado de trabalho (económicas), na estrutura familiar (sociais) e na organização do próprio Estado (políticas) tiveram impacto na vida dos cidadãos e cidadãs e na organização societária com a emergência de novas configurações de vulnerabilidade social. O novo modelo emergente de organização estatal e de proteção social, assente numa lógica de ativação e de responsabilização dos cidadãos (ãs) é objeto desta reflexão critica sobre a natureza instrumental e conceptual das políticas ativas. O cerne da discussão é colocado na natureza das políticas ativas enquanto instrumentos de intervenção do Estado, acreditando que assumem mais um caracter regulatório do que emancipatório. Este questionamento relaciona-se com dois eixos organizadores da racionalidade subjacente do presente artigo e que se consubstanciam nos argumentos neoliberais de organização da provisão estatal, nomeadamente ao nível das políticas públicas ativas e ainda no conceito de risco social assumido como um dos contornos identitários das estruturas sociais.

PALAVRAS-CHAVE: Sociedade de Risco. Risco. Estado Social. Políticas Ativas de Emprego.

\footnotetext{
${ }^{1}$ Doutorada em Serviço Social pela Universidade Católica Portuguesa. Professora Auxiliar de Serviço Social na Faculdade de Psicologia e Ciências de Educação da Universidade de Coimbra. Coimbra. Portugal. Telefone: +351962855271. E-mail: clarasantos@fpce.uc.pt. Instituição de Origem: Universidade de Coimbra (www.uc.pt)

${ }^{2}$ Licenciada em Serviço Social pelo Instituto Superior Miguel Torga, Coimbra, Pós-graduada em Proteção de Menores pela Faculdade de Direito da Universidade de Coimbra, Mestre em Família e Sistemas Sociais pelo Instituto Superior Miguel Torga, Coimbra e Aluna do Programa Doutoral Interuniversitário em Serviço Social da Universidade Católica Portuguesa e da Universidade de Coimbra. Telefone: +351918291406. E-mail: vanessa.crit@gmail.com. Instituição de Origem: Faculdade de Psicologia e Ciências da Educação da Universidade de Coimbra/Faculdade de Ciências Humanas da Universidade Católica Portuguesa.
} 


\begin{abstract}
The changes occurred in the transition from the first to the second modernity in the labor market(economic), in the family structure(social) and in the organization of the state itself (politics) had an impact on the citizen's life and on the organization of society with the emergence of new configurations of social vulnerability. The new emerging model of state organization and social protection, based on a logic of activation and accountability of citizens is the object of this critical reflection, especially on the instrumental and conceptual nature of active policies. The core of this discussion is placed in the nature of active policies as instruments of state intervention, believing that they assume a regulatory rather than an emancipatory character. This questioning is related to two organizing axes of the underlying rationality and are consubstantiated in the neoliberal arguments of organization of the state provision, namely in the level of active public policies and still in the concept of social risk assumed as one of the identity contours of the structures social rights.
\end{abstract}

KEYWORDS: Risk Society. Risk. Welfare State. Active Labour Policies.

\title{
INTRODUÇÃO
}

As políticas públicas, entendidas como "tudo aquilo que diz respeito ao espaço público” (SANTOS, 2016) podem ser analisadas no seu aspeto evolutivo onde foram integradas as contradições inerentes a um processo histórico (visível nos Países do Sul da América e no Sul da Europa) de lutas sociais e pactos contínuos entre Estado e Sociedade, bem como nos seus processos mais substantivos, onde identificamos o processo político no que diz respeito à definição de objetivos, aos conteúdos das decisões (usualmente de carácter macrossocial) e à sua dimensão material.

Quanto aos seus tipos, as políticas públicas podem ser distributivas, redistributivas e reguladoras. As políticas sociais distributivas são todas as ações de impacto público, levadas a cabo pelo Estado que têm como finalidade a distribuição pelos diferentes sectores da sociedade civil, em estreita relação com as dimensões consideradas fundamentais para uma sociedade de bem-estar social, como a habitação, a educação, a saúde, a ação e proteção social, das decisões políticas governamentais, bem como dos dividendos resultantes dos fundos inerentes ao capital social com uma alusão clara ao contrato social Rousseniano.

O critério de redistribuição das politicas públicas encontra-se relacionado com as instituições políticas e os seus conteúdos de acordo com os diferentes programas e decisões estratégicas dentro de cada sector, numa perspetiva atual de diferenciação positiva dos mecanismos de ação social, passando, na maior parte das vezes pela Serv. Soc. \& Saúde, Campinas, SP v. 14, n. 2 (20), p. 201-218, jul./dez. 2015 ISSN 1676-6806 
instauração de medidas políticas de proteção social, com um caráter reparador e de distribuição pecuniária em forma de subsídios e programas específicos para populações especificas, consideradas como mais vulneráveis.

A dimensão reguladora das políticas públicas centra-se, essencialmente, ao nível institucional, à ordem do sistema político e possui um caráter mais amplo do que as políticas distributivas e redistributivas, pois são estas que definem de forma mais abrangente como, quando, por quem e a quem vão ser endereçadas as políticas distributivas e redistributivas (FREY, 1997; MAURIEL, 2010).

Esta conceção instrumental dos objetivos das políticas públicas tinha, até finais do século XX, um sentido comumente aceite no sistema dual de Estado e Cidadão. No entanto, as mudanças e desafios colocados ao Estado, pelas transformações ocorridas no mercado de trabalho (económicas), na estrutura familiar (sociais) na sua própria organização (políticas), decorrentes da passagem da primeira para a segunda modernidade, tiveram impacto na vida dos cidadãos e cidadãs e na organização societária com a emergência de novas configurações de vulnerabilidade social, principalmente ao nível do emprego e das estruturas sociais com um consequente aumento da população em situação de "mal estar social”", apresentando dificuldades em integrar o mercado de trabalho.

As mudanças ocorridas dentro das três dimensões enunciadas (económicas, sociais e políticas) remetem, de acordo com Beck (1999, 2015) e Giddens (2000) para uma racionalidade subjacente à organização social relacionada com os novos riscos sociais e com a sociedade de risco onde a intervenção do Serviço Social é, atualmente, um espaço no seio do qual se debatem, quotidianamente, os dramas dos cidadãos que vivem uma realidade aparentemente geradora de clivagens e de exclusão.

É neste modelo emergente de organização das práticas sociais que o cerne da discussão é colocado. Isto é como é que a natureza das políticas ativas enquanto instrumentos de intervenção do Estado assumem efetivamente um caráter emancipatório (retórica discursiva política) ou um caracter regulador? Este questionamento relaciona-

\footnotetext{
3 “[...] políticas activas, por se fazerem acompanhar de elevadas obrigações para os desempregados, tendem a responsabilizar estes pela sua situação de exclusão, descartando assim os patrões, as empresas e o capital de qualquer responsabilidade por tal situação (GELDOF, 1999: BERKEL, 1999). E, por fim, elas tendem a gerar um mercado de trabalho secundário, de ocupações meramente temporárias e de empregos inapropriados a conduzir à efectiva inserção profissional dos trabalhadores activados (HVINDEN, 1999), in: HESPANHA, 2002, p. 7.
}

Serv. Soc. \& Saúde, Campinas, SP v.15, n. 2 (22), p. 201-218, jul./dez. 2016 ISSN 1676-6806 
se com dois eixos organizadores da racionalidade subjacente ao presente artigo e que se consubstanciam nos argumentos neoliberais de organização da provisão estatal, nomeadamente ao nível das políticas públicas ativas e ainda no conceito de risco social, assumido como um dos contornos identitários das estruturas sociais.

\section{Os riscos na Sociedade de Risco}

O surgimento dos "novos riscos sociais" colocou à prova o "velho" Estado Social, sendo mais visível a partir dos anos 80 do séc. XX, que parece não conseguir dar resposta às exigências de um mundo economicamente globalizado, marcado pela hegemonia das políticas neoliberais que ideologicamente defendem a retração do Estado em prol de um Estado mínimo e “exigem” políticas de contenção orçamental com vista à “sustentabilidade da despesa pública” estatal (MARTINS, 2015).

Assiste-se a uma restruturação do Estado social com a mudança de paradigma da ação pública mais focalizada na ideia de Estado social ativo - um novo modo de regulação estatal assente na centralidade das políticas de ativação, por oposição a um Estado social passivo, no qual as políticas asseguram a defesa dos direitos sociais sobre a forma de assistência e indemnização, de modo a compensar os desequilíbrios provocados pelo sistema político e económico (MARTINS, 2015).

O Estado social ativo assume uma lógica de ativação dos indivíduos, responsabilizando-os pelas suas decisões e trajetórias de vida, individualizando as respostas face aos riscos sociais (BECK, 2015) e tornando-os autónomos, colocando em relevo a reciprocidade entre direitos e deveres. Os indivíduos só conseguem aceder aos direitos sociais (apoios do Estado) se cumprirem os deveres impostos pelo Estado, isto é, este último parece exerce um controlo sob os indivíduos através das políticas de ativação (DUBOIS, 2007).

Para que o sistema social continue a subsistir, muitos Estados optam pela "terceira via"4 ou o fortalecimento do terceiro setor na coisa pública com apelo

\footnotetext{
${ }^{4}$ A "terceira via” é uma proposta de Anthony Giddens que procura uma solução onde convergissem dois modelos oposto de organização política e económica - o Modelo Social Europeu e o Modelo Neoliberal. Começou ser desenvolvida nos anos 80, do séc. XX, mas ganhou força no final dos anos 90 com o apadrinhamento de Tony Blair, o Primeiro-Ministro britânico na altura.

Serv. Soc. \& Saúde, Campinas, SP v. 14, n. 2 (20), p. 201-218, jul./dez. 2015 ISSN 1676-6806
} 
crescente à participação de novos atores sociais na arena política da proteção social, nomeadamente ONG’s, associações e mesmo empresas e entidades do setor económico. Neste mesmo contexto, Hespanha (2008) afirma que o conceito de “cidadão” nas relações dos indivíduos com os sistemas de proteção social introduz-se numa

[...] filosofia de cidadania que estava afastada na clássica relação paternalista entre Estado e assistido, geradora de dependência e pela qual este último se tende a tornar num sujeito subordinado (p. 6).

Significa, pois, que a “obrigação” da proteção social não é só da parte do Estado, mas também de toda a sociedade civil, e ainda do próprio cidadão o que afasta a ideologia do direito social para uma nova ideologia de corresponsabilização do beneficiário que se assume como protagonista nos projetos de mudança social.

\subsection{A Sociedade de Risco e os novos riscos sociais}

O conceito de Sociedade de risco foi apresentado por Ulrich Beck, em 1986, e diz respeito ao desenvolvimento de novos riscos que começam na segunda metade do século XX (BECK, 2015, p. 28), designada por Beck (1999, 2015) e Giddens (2000) como segunda modernidade ou modernidade tardia $^{5}$. Nesta, reconhece-se que a tecnologia e a ciência geram benefícios ao ser humano, mas também geram consequências inesperadas e indesejadas. São efeitos secundários e colaterais não desejáveis, de natureza complexa, imprevisível e mesmo incontrolável, onde o Estadonação parece não conseguir regular os riscos de alta complexidade, principalmente, aqueles que têm uma espacialidade e uma temporalidade que vão além das fronteiras geopolíticas nacionais. Nesta senda, os efeitos dos riscos sociais ampliam-se e o seu controlo é limitado.

Situação oposta à sociedade moderna, onde os riscos sociais eram passíveis de serem categorizados e se acreditava que podiam ser controlados, exatamente pelas suas próprias vitórias. A categoria de sociedade de risco “tematiza o processo de questionamento, a ideia da controlabilidade e compensabilidade das incertezas e perigos

\footnotetext{
${ }^{5}$ Em Beck (1999, 2015), modernidade refere-se sempre à sociedade industrial e ao conhecimento científico produzido, principalmente, até o século XIX. A sociedade pósindustrial do fim do século XX é chamada de segunda modernidade, modernidade pós-industrial ou modernidade tardia.
}

Serv. Soc. \& Saúde, Campinas, SP v.15, n. 2 (22), p. 201-218, jul./dez. 2016 ISSN 1676-6806 
industriais gerados” (BECK, 2015, p. 28) e resume uma época que questiona os efeitos secundários de uma modernização bem-sucedida, em que os sentimentos de insegurança e incerteza são generalizados e democratizados, no sentido em que atinge todos, e contra os quais não existe uma resposta que proteja a sociedade. Este fato gera medo, premiando a segurança em prol das liberdades e dos princípios democráticos.

O conceito de risco, de acordo com Beck, diz respeito "a perigos futuros tematizados no presente, resultantes, frequentemente, dos avanços da civilização" (2015, p. 22). Portanto, o risco é uma antecipação de uma possível catástrofe, isto é, o risco é a possibilidade de algo acontecer no futuro, mas que está omnipresente no nosso quotidiano e orienta as nossas ações, "transforma-se numa força política que muda o mundo", portanto, "o risco mundial é a encenação da realidade do risco mundial” (BECK, 2015, p. 32).

A categoria do risco permite a ligação entre o conhecido e o desconhecido no horizonte da probabilidade (cálculo do risco), permitindo lidar com a insegurança, que só pode ser superada pelo conhecimento, mas que foi criada por conhecimento, portanto, o não-conhecimento (BECK, 2015). Nesse sentido, Carapinheiro (2005) coloca em relevo a dimensão política do discurso do risco por causa da "ausência de conhecimento sobre os fundamentos científicos que subjazem à proliferação de múltiplos riscos” (ibid, p. 199).

Nas sociedades modernas existe uma nova forma de organização social e um novo estatuto para o indivíduo, em que a coesão social não se faz anulando os indivíduos, mas integrando as especificidades e as liberdades individuais. Daqui, surge a necessidade de mecanismos internos de regulação, de modo a evitar a insegurança total. Os riscos sociais, anteriormente vistos como coletivos, passam a assumir uma configuração individual, em que passam a ser perspetivados como riscos sociais privatizados, que se traduzem em políticas de carácter mais individual, pessoal e assistencial. Os indivíduos são cada vez mais responsabilizados pelas suas escolhas e percursos de vida e os riscos são individualizados.

De acordo com Taylor-Gooby (2004), os novos riscos sociais são os riscos com que as pessoas lidam ao longo da sua vida resultantes de mudanças económicas e sociais associadas à transição para a sociedade pós-industrial. No mesmo sentido, Bonoli Serv. Soc. \& Saúde, Campinas, SP v. 14, n. 2 (20), p. 201-218, jul./dez. 2015 ISSN 1676-6806 
(2004) considera que os “novos riscos sociais” se referem a situações em que os indivíduos experienciam perdas de bem-estar e que surgiram como resultado das transformações socioeconómicas das sociedades pós-industriais, acima de tudo a terciarização do emprego e da entrada maciça das mulheres no mercado de trabalho. Ambos os autores fazem uma leitura dos riscos sociais ao longo do ciclo de vida, em que cada fase do ciclo vital implica novos riscos sociais.

Taylor Gooby (2004) identifica as principais mudanças ocorridas na sociedade pós-industrial e os novos riscos sociais gerados que, segundo ele, aumenta o número de pessoas em situação de vulnerabilidade social:

a)Mudanças na família e nos papéis de género (entrada em grande escala da mulher no mundo do trabalho): a.1. Equilíbrio entre atividade remunerada e as responsabilidades familiares. a.2. Destruturação do apoio familiar a dependentes

b)Mudanças no mercado de trabalho (maior exigência de competências e aptidões técnicas, bem como uma maior competição a nível global, fez com que as pessoas com mais baixos níveis de escolaridades estejam mais vulneráveis ao risco de exclusão social): b.1. Falta de competências necessárias que permitam ter acesso a empregos seguros e bem pagos; b.2. Ter competências e formação que se tornaram obsoletas e sendo incapaz de atualizá-las através de aprendizagens ao longo da vida

c)Mudanças no Estado-providência: Tendência de privatizar, o que não fornece serviços satisfatórios, embora a privatização não seja em si mesma um risco;

Bonoli (2004, 2007), no mesmo sentido, considera que as transformações socioeconómicas da sociedade pós-industrializada - a desindustrialização e a terciarização do trabalho, a entrada massiva das mulheres no mercado de trabalho, aumento da instabilidade da estrutura familiar e a "despadronização" do emprego alteraram as estruturas do risco social nas sociedades ocidentais e resultaram no surgimento de novos grupos de risco que claramente não pertencem à clientela tradicional do Estado social do pós-guerra e ainda enfrentam grandes perdas de bemestar. Ao longo das últimas três décadas, em conjunto com os esforços destinados a 
conter o crescimento das despesas sociais, vimos o surgimento de novas políticas que vão de encontro às necessidades desses grupos sociais (BONOLI, 2004).

De acordo com as definições e identificação dos novos riscos sociais de Bonoli e Taylor-Gooby, poderemos desenhar o seguinte quadro-resumo:

Quadro 1 - Quadro-Resumo das mudanças ocorridas nas sociedades pós-industriais e consequências

\begin{tabular}{|c|c|c|}
\hline MUDANÇAS & CONSEQUÊNCIAS /“NOVOS” RISCOS SOCIAIS & $\begin{array}{l}\text { GRUPOS MAIS } \\
\text { VULNERÁVEIS AOS } \\
\text { “NOVOS” RISCOS } \\
\text { SOCIAIS }\end{array}$ \\
\hline $\begin{array}{l}\text { Mudanças nas } \\
\text { estruturas } \\
\text { familiares e nos } \\
\text { papéis de } \\
\text { género }\end{array}$ & $\begin{array}{l}\text { Entrada massiva das mulheres no mercado de trabalho - } \\
\text { Dificuldade de conciliar a vida familiar e trabalho; } \\
\text { Novas configurações de família - aumento de famílias } \\
\text { monoparentais }\end{array}$ & $\begin{array}{l}\text { Famílias com filhos } \\
\text { pequenos e/ou idosos } \\
\text { Famílias monoparentais } \\
\text { Mulheres trabalhadoras } \\
\text { Jovens }\end{array}$ \\
\hline $\begin{array}{l}\text { Mudanças no } \\
\text { mercado de } \\
\text { trabalho }\end{array}$ & $\begin{array}{l}\text { Desindustrialização e a terciarização do trabalho - } \\
\text { desemprego dos trabalhadores industriais (com baixas } \\
\text { qualificações) e predomínio do setor dos serviços: } \\
\text { Falta de competências necessárias que permitam ter } \\
\text { acesso a empregos seguros e bem pagos (desemprego e } \\
\text { trabalho precário); } \\
\text { Ter competências e formação que se tornaram obsoletas e } \\
\text { sendo incapaz de atualizá-las através de aprendizagens ao } \\
\text { longo da vida. } \\
\text { Despadronização do trabalho - Passagem do trabalho a } \\
\text { tempo inteiro e durante toda a vida para trabalho em part- } \\
\text { time e fragmentado ao longo da vida: } \\
\text { Reflexo no sistema contributivo de pensões/reformas }\end{array}$ & $\begin{array}{l}\text { Trabalhadores com baixas } \\
\text { qualificações e/ou } \\
\text { competências obsoletas } \\
\text { Jovens } \\
\text { População Idosa }\end{array}$ \\
\hline $\begin{array}{l}\text { Mudanças no } \\
\text { Estado Social }\end{array}$ & $\begin{array}{l}\text { Tendência de expansão dos serviços privados, outrora } \\
\text { assegurados pelo Estado, que não fornece serviços } \\
\text { satisfatórios. } \\
\text { Embora a privatização não seja em si mesma um risco, } \\
\text { pode gerar novos riscos quando os cidadãos-consumidores } \\
\text { se comprometem com escolhas insatisfatórias e quando a } \\
\text { regulação das normas do privado é ineficaz. } \\
\text { Cobertura insuficiente da segurança social }\end{array}$ & População de forma geral \\
\hline
\end{tabular}

Fonte: Elaborado pelas autoras, baseado em Taylor-Gooby (2004) e Bonoli (2004, 2007)

O pacto social em que este novo modelo assenta, pesa, não só no capital e no trabalho sob a égide do Estado, mas também na sociedade que deve encarar os esquemas de proteção e segurança social não como mecanismos subsidiários e de solidariedade mecânica, mas como uma necessidade construída socialmente (isto é uma Serv. Soc. \& Saúde, Campinas, SP v. 14, n. 2 (20), p. 201-218, jul./dez. 2015 ISSN 1676-6806 
necessidade e um bem coletivo) de proteção social das populações mais vulneráveis. Esta implicação mútua entre indivíduo e sociedade, afasta-se quer do direito social tradicional quer da ajuda social paternalista e, por isso, as obrigações são recíprocas: uma responsabilização do beneficiário considerado ator do seu próprio futuro e uma obrigação de meios por parte da sociedade (FERREIRA, 2008).

\section{O espetro das desigualdades sociais}

As desigualdades sociais levam à exclusão de um grande número de pessoas e o sistema apresenta dificuldades em dar respostas e criar soluções que ajudem a mitigar esta questão. Vivemos numa época em que a incerteza e risco conduzem a vulnerabilidades e desigualdades sociais e à exclusão social, as quais são resultantes da degradação da função integradora do trabalho. Segundo Pintelon et al. (2011), os riscos sociais são definidos como circunstâncias socioeconómicas que resultam numa significante perda de rendimentos e, consequentemente, num provável aumento de pobreza.

Parece-nos que coexistem formas de atuação onde se observam privatizações de serviços e capitais, uma retração do Estado no investimento social e na gestão pública dos processos de provisão social, a par com uma partilha de responsabilidade pelo bemestar "entre o Estado e a sociedade, nomeadamente com a sociedade civil/terceiro sector e com os indivíduos” (HESPANHA; FERREIRA; PACHECO, 2013, p. 213). É o que os autores designam por "Shumpeterian Workfare Postnational Regime". Nesta lógica, o atual Estado procura um casamento feliz entre princípios liberais protetores da economia e os princípios do Estado Providência. Se o contrato utilizado nos permite utilizar a metáfora do casamento, a condição da sua felicidade permite-nos questionar a mesma.

Esta perspetiva enquadra-se no que Jessop (1999) argumenta ser a resolução do paradoxo de Offe $^{6}$ (in JESSOP, 1999, p. 1) e que passa necessariamente pelo debate do papel dos Estados de bem-estar social na reprodução social e económica. Este debate só pode ser realizado de forma singular tendo em conta a forma como os diferentes

\footnotetext{
${ }^{6} \mathrm{O}$ paradoxo de Offe argumenta que a resolução ou a gestão da crise deverá ser determinada na agenda política pela constatação que o capitalismo não pode coexistir com, nem pode existir sem o Estado Social. Serv. Soc. \& Saúde, Campinas, SP v.15, n. 2 (22), p. 201-218, jul./dez. 2016 ISSN 1676-6806
} 
governos organizam os sistemas de bem-estar social e a sua governação. Significa que o capitalismo como modelo de produção económica centra-se na perspetiva do desenvolvimento dos mercados e na produção de riqueza. Logo, o Estado deve assumir diferentes posições face à aplicação de políticas sociais. Para Jessop (1999) esta distinção é fundamental numa organização “ideal” de funcionamento social, onde as políticas económicas e as políticas sociais são politicamente mediadas e os modos de organização governamental não devem tentar fazer coincidir a vida económica e a vida social nacional.

O acesso a direitos sociais e a defesa pela sua continuidade é uma questão fundamental do direito de cidadania, isto é, configura-se como uma questão duplamente individual e coletiva. Individual, na medida em que para cada cidadão o aumento das desigualdades sociais é percecionado como uma forma de injustiça social e de ataque ao regime democrático em vigor. Coletivo, porque a consciência crítica nacional se encontra comprometida com as consequências e o sentimento de injustiça social que não permitem, atualmente, uma participação cívica em paridade, contribuindo para o aumento de fraturas sociais graves, das quais as situações de pobreza e exclusão social são uma das faces mais visíveis desta condição. Em consequência observamos o risco da coesão societária. Esta, está estritamente relacionada com a sua capacidade de fazer face aos múltiplos riscos derivados quer do próprio ambiente social e económico, quer das organizações e medidas sociais públicas. No entanto, as medidas de austeridade, o aumento da precariedade, a perda da confiança no Estado e nos seus organismos bem como o descrédito sentido em vários países face à sua legitimidade, complexificam o sistema de proteção social atual e consequentemente a capacidade do cidadão a ele acederem.

Ora, o nosso argumento é de que apesar das políticas sociais ativas serem uma das mais paradigmáticas do quadro político atual e que na sua essência perseguem o entendimento do sujeito/cliente dos serviços de ação social de uma forma holística (isto é visando a sua integração e a sua inserção - utilizando a perspetiva de CASTEL, 1991) elas têm sido alvo de grandes críticas, pois a sua implementação encontra-se divorciada da sua ideologia central. Em larga medida, a "prática está a tornar-se mais instrumental do que substantiva, mais preocupada com os resultados do que com os 
processos” (BRANCO; AMARO, 2011, p. 662). Ou dito ainda de outra forma, o reconhecimento do sujeito enquanto cidadão de direitos e de participação social está dependente da capacidade deste em fornecer ou não a “contrapartida” destas políticas de proteção social defensoras da integração do mesmo no mercado de trabalho e reconhecendo-o somente como sujeito quando ele cumpre os mesmos.

A conceção do cidadão encontra-se, a nosso ver, perversamente invertida neste jogo político e de acesso a benefícios e direitos sociais, uma vez que os sistemas de ação social incapazes (na maior parte das vezes, mais por razões de caráter instrumental do que por razões de capacidade reflexiva e técnica) de realizarem um diagnóstico centrado no sujeito e nos seus contextos, focalizam-se essencialmente nas questões tecnocráticas, administrativas e regulamentares esvaziadas no reconhecimento da identidade individual e social do cidadão.

\section{Políticas Ativas de Emprego: emancipatórias ou reguladoras?}

O (des)emprego estrutural é uma das facetas relacionadas com a democratização do risco em que as consequências ultrapassam o aspeto individual e repercutem-se no coletivo social, sendo um dos desafios aos modelos de Estado Social que assistem a um aumento crescente do número de beneficiários/utentes cidadãos das políticas/medidas ativas de emprego. O desemprego, a proliferação da precariedade e da flexibilidade nas relações laborais colocam desafios ao papel do Estado, como instituição de cobertura dos indivíduos face aos riscos sociais. Neste sentido, é visível o estabelecimento de parcerias entre o Estado e instituições privadas para a cobertura dos riscos sociais e a consolidação do bem-estar social, dando origem ao designado Welfare mix. O Estado assume um novo papel delegando responsabilidades em entidades privadas e/ou nos próprios indivíduos (individualização do risco).

As políticas ativas de emprego são, igualmente, reflexo desta nova forma de Estado Social, colocando a tónica nos indivíduos e os responsabilizando pelo seu percurso de (re)inserção profissional. Valadas (2013) refere-se a estas políticas como “políticas de empregabilidade autónoma”.

O conceito de ativação não é unanime, discutido por alguns autores como um conceito vago, aberto a várias leituras e interpretações ideológicas (GELDOF, 1999). 
Para Matti Heikkilä (1999) este conceito pode estar relacionado com as questões de emprego, mas também com questões de inserção social. Já Roche (1992, citado por HESPANHA, 2008) considera que as políticas de ativação implicam a inserção na sociedade, através da realização de tarefas socialmente úteis, promovendo assim uma “participação ativa”. Geldof (1999) refere que as políticas ativas devem ser focadas nos indivíduos dependentes de subsídios, inserindo-os no mercado de trabalho, o que proporciona o acesso à plena cidadania (caráter emancipatório). Hespanha (2008) e Hespanha e Matos (2000) colocam em relevo a dimensão de contratualização e controlo implícita na ativação, isto é, só tem direito quem contribui com uma atividade socialmente útil.

Em contraste existe, igualmente, um discurso científico e político apologista do Estado Ativo e dos seus consequentes programas sociais e medidas políticas. Nesta postura, identificamos argumentos que apontam como vantagens destas medidas a poupança de capital económico, permitindo reduzir os gastos com subsídios de desemprego e outro tipo de apoios financeiros, evitando a subsidiodependência e preocupando-se com os direitos sociais básicos, nomeadamente o direito ao trabalho (GELDOF, 1999). Outro aspeto positivo é o de aumentar a participação no mercado de trabalho proporcionando uma melhoria das qualificações e estimulando a empregabilidade, ao mesmo tempo que desenvolve a autonomia e autoestima dos trabalhadores. Estas políticas possuem, nestes argumentos, um carácter potencialmente emancipatório, uma vez que colocam como epicentro da sociedade a ética do trabalho e possibilitam o acesso à plena cidadania (BOSCO; CHASSARD, 1999; HEIKKILÄ, 1999; HVINDEN, 1999; GELDOF, 1999).

Às políticas de ativação são também atribuídas diversas desvantagens e “armadilhas” discursivas (HESPANHA; MATOS, 2000). Uma das grandes críticas prende-se com o fato destas políticas terem um carácter punitivo, uma vez que só recebe ajuda quem cumpre com o que o Estado "impõe", condicionando assim o acesso a benefícios sociais. Este aspeto também limita a autonomia e liberdade dos trabalhadores, ao mesmo tempo que se assiste a uma redução de bem-estar por realizarem atividades socialmente pouco valorizadas, degradantes e mesmo impróprias para a inserção profissional, minando os direitos universais e a dignidade dos 
indivíduos, o que pode ser indicador de riscos sociais levando à criação de novos grupos de excluídos. Um outro aspeto negativo apontado são as elevadas obrigações atribuídas aos indivíduos responsabilizando-os pela sua situação, excluindo as responsabilidades das entidades empregadoras, do Estado e do mercado. O fato dos indivíduos não terem os mesmos direitos dos outros trabalhadores e estatuto é outro dos aspetos negativos a ter em conta. Por fim, as políticas ativas tendem a criar mercados de trabalho alternativos de ocupações temporárias que não conduzem a uma real inserção profissional (HESPANHA; MATOS, 2000; HESPANHA, 2008; HEIKKILÄ, 1999, HVINDEN, 1999; GELDOF, 1999).

Resumindo, os defensores das políticas ativas acreditam que estas ajudam a promover a inserção e inclusão de todos na sociedade e no mercado de trabalho, permitindo ao Estado uma diminuição dos encargos/gastos sociais. Por outro lado, os opositores destas políticas acreditam que elas são excludentes e acabam por marginalizar certos segmentos da população.

Na lógica dos potenciais beneficiários/ cidadãos utentes destas políticas, observamos que nem todos os indivíduos possuem as caraterísticas necessárias que lhes permitem a "ativação”, que lhes possibilite "encaixarem-se” nas políticas ativas. Desta distinção entre os cidadãos que estão “dentro" e os cidadãos que estão “fora” do sistema questionamos se as políticas de ativação podem conduzir ao agravamento das desigualdades sociais pelos contextos de exclusão socioeconómica que direta ou indiretamente tendem a gerar.

Hespanha e Matos (2000) consideram que a reciprocidade implícita entre direito e dever pode gerar um grave problema de controlo social e marginalização, uma vez que o Estado pode exigir o cumprimento de um dever desproporcional em troca de ajuda. $\mathrm{O}$ lado impositivo da ativação pode levar a que a margem de negociação dos cidadãos e cidadãs desapareça e que a "resistência ao pronto-a-vestir das políticas venha a ser julgada como uma conduta ilegítima e, portanto, não merecedora de proteção” (HESPANHA, 2008, p.15). Este aspeto é deveras importante, uma vez que podemos estar a assistir a uma estigmatização e exclusão da população desempregada, que tende a aumentar. Martins (2015, p. 170), por sua vez, levanta a hipótese da ideologia da ativação poder vir a ser "um poderoso mecanismo de legitimação das desigualdades sociais e da reprodução da denominação social”. 


\section{CONSIDERAÇÕES FINAIS}

Acreditamos que as Políticas Ativas têm um carácter fortemente regulatório, ao contrário da filosofia subjacente de emancipação dos cidadãos e cidadãs e que este caracter regulatório parece conduzir ao agravamento das desigualdades sociais pelos contextos de exclusão socioeconómica que direta ou indiretamente tendem a gerar, uma vez que nem todos os indivíduos possuem características que lhes permitam a “ativação”.

Por outro lado, a dicotomia regulação versus emancipação parece estar relacionada com a segmentarização das medidas de proteção social em prol das diversas necessidades que os cidadãos acarretam, onde a diminuição ou inexistência de rendimentos económicos não parece ser a base central da ação social. Neste sentido e num contexto estratégico da intervenção social em contextos limite da sobrevivência humana utilizamos os mesmos eixos de Castel (1990):

a) Um eixo de equilíbrio e de gestão da “integração” e da “não Integração” dos sujeitos no seu contexto social. Este eixo legitima a inclusão social pelo trabalho/emprego.

b) Um eixo de equilíbrio e de gestão da "inserção" e da "não-inserção" dos sujeitos nos seus contextos de sociabilidade em redes sólidas de suporte em todos os vetores que dão sentido emocional, social pessoal ao cidadão e à cidadã.

Estes dois eixos parecem-nos fundamentais na conceção do planeamento da ação social por parte do Serviço Social e devem ser tidos em conta de forma holística e concomitante.

No entanto, nestas circunstâncias específicas de vulnerabilidade extrema, encontramo-nos num espaço simbólico de difícil intervenção uma vez que estes cidadãos (não pertencentes, na sua maioria, a uma pobreza tradicional e transgeracional) possuem características que os colocam num "patamar intermediário” de análise social. Isto é, podem ser observados através de duas perspetivas (GARCIA, 2006): (i) desvinculação face a uma determinada situação concreta, grandemente influenciada pela detioração do mercado de trabalho enquanto eixo central dos processos de inclusão Serv. Soc. \& Saúde, Campinas, SP v. 14, n. 2 (20), p. 201-218, jul./dez. 2015 ISSN 1676-6806 
social (YÉPEZ DE CASTILHO, 1994; CASTEL, 1998), bem como pela consequência das medidas de austeridade e situações de precariedade a que assistimos em toda a Europa bem como no continente Americano; e, (ii) desvinculação como retrato de uma condição em contraposição ao caráter processual deste fenómeno.

O presente contexto enquadra-se na visão de Messu (1994) onde uma situação de “não-integração” é, igualmente, (além dos movimentos sociais e políticos de caráter macro) uma situação vivida por indivíduos com capacidade de realizar um julgamento sobre a mesma e agir em conformidade. É neste contexto que a inquietude social assume contornos avassaladores. O sentimento de incerteza, o medo quanto ao futuro, o aumento exponencial da nova pobreza e a falta de confiança nos dirigentes políticos que representam os cidadãos é visível no aumento de movimentos sociais e de manifestações públicas de contestação contra quer os atos governamentais nacionais, como contra os processos de regularização económica europeia.

\section{REFERÊNCIAS}

BECK, U. Sociedade de Risco Mundial: em busca da segurança perdida. Lisboa: Edições 70, 2015.

BECK, U. World Risk Society. Cambridge: Polity Press, 1999.

BERKEL, R. van; COENEN, H.; DEKKER, A. (1999) Regulating the unemployed: from protection to participation. In: LIND, J.; HORNEMANNI, I. (eds.) Inclusion and Exclusion: unemployment and non-standard Employment in Europe. Ashgate, Aldershot, 89-109.

BONOLI, G. The political economy of active labour market policy. Politics \& Society, vol. $38 n^{\circ}$ 4, p. 435-457, 2010.

BONOLI, G. Postindustrialization, New Social Risks, and Welfare State Adaptation in Advanced Industrial Democracies. Comparative Political Studies, vol. 40, $\mathrm{n}^{\mathrm{o}}$ 5, p. 495-520, 2007.

BONOLI, G. Modernising post-war welfare states: Explaining diversity in patterns of adaptation to new social risks. Paper presented at the $2^{\text {nd }}$ ESPAnet Annual Conference, Oxford, 9-11 September 2004. 
BOSCO, A.; CHASSARD, Y. A shift in the Paradigm: Surveying the European Union Discourse on Welfare and Work. In European Foundation for the Improvement of Living and Work Conditions. Linking Welfare and Work, 1999, p. 43-58.

BRANCO, F.; AMARO, I. As práticas do «Serviço Social activo» no âmbito das novas tendências da política social: uma perspectiva portuguesa. Serviço Social \& Sociedade, vol. 108, p. 656-679, 2011.

CARAPINHEIRO, G. A globalização do risco social. In SANTOS, B. (Org.). Globalização: Fatalidade ou Utopia? 3. ed. Porto: Afrontamento, 2005, p. 197-229.

CASTEL, R. (1998). Le roman de la désaffiliation. À propos de Tristan et Iseut', Le Débat, n. 61, (4) : 155-167.

CASTEL, R. De l'indigence à l'exclusion, la désaffiliation : précarité du travail et vulnérabilité relationnelle', DONZELOT, J (Dir.) Face à l'exclusion, le modèle français. Paris: Editions Esprit, 1990, 1991.

DUBOIS, V. Estado social ativo e controlo dos desempregados: uma viragem rigorosa entre tendências europeias e lógicas nacionais. Sociologia, n. 17/18, p. 11-31, 2007.

ESTANQUE, E. O Estado Social em Causa: instituições sociais, políticas sociais e movimentos sociolaborais. Finisterra - Revista de Reflexão e Crítica, Lisboa, ${ }^{\circ} 73$, p. 39-80, 2012.

FREY, K. Políticas Públicas: Um Debate Conceitual e Reflexões Referentes à Prática da Análise de Politicas Publicas no Brasil. Tese de Dissertação de Doutoramento sobre as Políticas Ambientais dos Municípios de Santos e Curitiba. Departamento de Ciências Sociais e do Núcleo Interdisciplinar de Políticas Públicas da Pontifícia Universidade Católica de Paraná, 1997.

GARCIA, B. La situación laboral precária: marcos conceituales e ejes analíticos pertinente. Revista Trabajo Social, ano 2, nº 3, Julio-deciembre de 2006, OIT-México. GIDDENS, A. O mundo na era da globalização. Lisboa: Editora Presença, 2000.

GELDOF, D. New activation policies: promises and risks. In: European Foundation for the Improvement of Living and Work Conditions. Linking Welfare and Work, 1999, p. 13-26.

HEIKKILÄ, M. A brief introduction to the topic. In: EUROPEAN FOUNDATION FOR THE IMPROVEMENT OF LIVING AND WORK CONDITIONS. Linking Welfare and Work, 1999, p. 5-12.

Serv. Soc. \& Saúde, Campinas, SP v. 14, n. 2 (20), p. 201-218, jul./dez. 2015 ISSN 1676-6806 
HESPANHA, P.; FERREIRA, S.; PACHECO, V. O Estado social, crise e reformas. In: Anatomia da crise: identificar os problemas para construir alternativas. Coimbra: Centro de Estudos Sociais, 2013, p. 161-249.

HESPANHA, P. Políticas Sociais: Novas Abordagens, Novos Desafios. Revista de Ciências Sociais, Universidade Federal do Ceará, vol. 39, nº 1, 2008, p. 5-15.

HESPANHA, P. Mal-estar e risco social num mundo globalizado: Novos problemas e novos desafios para a teoria social. In: SANTOS, B. (Org.). Globalização: Fatalidade ou Utopia? 3. ed. Porto: Afrontamento, 2005, p. 163-196.

HESPANHA, P.; MATOS, A. Compulsão ao trabalho ou emancipação pelo trabalho? Para um debate sobre as políticas activas de emprego. Sociologias, Porto Alegre, ano 2, $\mathrm{n}^{\mathrm{o}}$ 4, 2000, p.88-109.

HESPANHA, P. La Reforma del Estado y de la Administración Pública. Comunicação apresentada ao VII Congreso Internacional del CLAD 8-11 Oct 2002. Lisboa.

HVINDEN, B. Activation: a Nordic Perspective. In: EUROPEAN FOUNDATION FOR THE IMPROVEMENT OF LIVING AND WORK CONDITIONS. Linking Welfare and Work, 1999, p. 27-42.

JESSOP, B. From Keynesianism to Workfarism. In: LEWIS, G.; KEYNES, M. Rethinking Welfare Policy. Open University Press, 1999.

MARTINS, J. E. O Estado social ativo: Um novo paradigma legitimador das políticas públicas em Portugal. Revista Crítica de Ciências Sociais, nº 108, 2015, p. 157-174.

MAURIEL, A. Pobreza, seguridade e assistência social: desafios do enfrentamento à ‘questão social’. Katálysis, Florianópolis, vol. 13, n² 2, 2010, p. 270-275.

PINTELON, O., CANTILLON, B., VAN DEN BOSCH, K.; WHELAN, C.T. The Social Stratification of Social Risks: Class and Responsibility in the "New" Welfare State. Amsterdam: AIAS, GINI Discussion Paper 13, 2011.

TAYLOR-GOOBY, P. The New Welfare State Settlement in Europe. European Societies, Vol. 10, $\mathrm{n}^{\circ}$ 1, 2008, p. 3-24.

TAYLOR-GOOBY, P. New Risks, New Welfare: The Transformation of the European Welfare State. New York: Oxford University Press, 2004.

SANTOS, C. Social Policy: From the Death of Welfare State to the State "Nameless". An historic overview of Social Policies in South and Eastern Countries Journal of Social Theory, Empirics, Policy and Practice. Vilnius: Leidyka University, $\mathrm{n}^{\circ} 13$, 2016, p. 41-54. 
VALADAS, C. Mudanças nas políticas: Do (des)emprego à empregabilidade. Revista Crítica de Ciências Sociais, nº 102, p. 89-110, 2013. 